\title{
Review Article \\ Polylactic Acid Based Nanocomposites: Promising Safe and Biodegradable Materials in Biomedical Field
}

\author{
Lili Sha, ${ }^{1,2}$ Zhaofeng Chen, ${ }^{1,2}$ Zhou Chen, ${ }^{1,3}$ Aili Zhang, ${ }^{3}$ and Zhaogang Yang ${ }^{3}$ \\ ${ }^{1}$ College of Material Science and Technology, Nanjing University of Aeronautics and Astronautics, Nanjing 210016, China \\ ${ }^{2}$ Suqian NUAA Institute of New Materials and New Equipment Manufacturing Co., Ltd., Suqian 223800, China \\ ${ }^{3}$ Nanoscale Science and Engineering Center, The Ohio State University, Columbus, OH 43210, USA
}

Correspondence should be addressed to Zhaofeng Chen; cz6327725@163.com and Zhaogang Yang; yzhaogang@gmail.com

Received 28 June 2016; Accepted 31 August 2016

Academic Editor: Ming Zhang

Copyright (C) 2016 Lili Sha et al. This is an open access article distributed under the Creative Commons Attribution License, which permits unrestricted use, distribution, and reproduction in any medium, provided the original work is properly cited.

\begin{abstract}
Polylactic acid (PLA) is widely used in biological areas due to its excellent compatibility, bioabsorbability, and degradation behavior in human bodies. Pure polylactic acid has difficulty in meeting all the requirements that specific field may demand. Therefore, PLA based nanocomposites are extensively investigated over the past few decades. PLA based nanocomposites include PLA based copolymers in nanometer size and nanocomposites with PLA or PLA copolymers as matrix and nanofillers as annexing agent. The small scale effect and surface effect of nanomaterials help improve the properties of PLA and make PLA based nanocomposites more popular compared with pure PLA materials. This review mainly introduces different kinds of PLA based nanocomposites in recent researches that have great potential to be used in biomedical fields including bone substitute and repair, tissue engineering, and drug delivery system.
\end{abstract}

\section{Introduction}

Biological materials have experienced enormous development in the past 30 years. Even when there was an economic downturn near 2008, the usage of biomaterials maintains an increase of $13 \%$ every year, showing strong vitality and wide prospect. Fast development of biomaterials improved living standard of humans to a great extent. In the meantime, biomaterial science, which aims to search for perfect biocompatibility, improved interaction between cells and materials, tailored degradation rate, synthetical materials design, and other particular properties of polymers, metals, and ceramics, has also attracted much attention [1-11]. It is usually these three classes, either single ingredient or in many cases, composite ingredients, that are used as biomaterials [12-15].

Different from metal and ceramic, polymer offers an organic matrix and its molecular is easier to control $[16,17]$. It is relatively hard to define and conclude the physical and chemical performance of polymers because the properties of different polymers vary extremely. There are generally two categories of polymers, biodegradable and nonbiodegradable polymers. Biodegradable polymer is more environmentally friendly and frequently used for medical devices due to its excellent degradation behavior in human body and the purpose of environment protection. Degradation rate can also be controlled after some modification or by designing the proportion of different polymers in order to meet practical demands $[13,18]$. Biodegradable polymers then can be further divided into naturally derived materials and synthetically prepared materials. Among synthetically prepared materials, saturated poly- $\alpha$-hydroxyl esters are more commonly used in biomedical field, especially polylactic acid (PLA) [19]. The degradation products of PLA are usually water and carbon dioxide that do not cause any harm; more importantly, they can be cleared out of human body totally, making PLA the most popular biomedical material in the market.

PLA is a kind of linear aliphatic polyester derived from renewable resources such as corn, sugar, potato, and other agricultural products [20-22], whose properties are determined by many factors, such as the component isomers, 
preparing temperature, and molecular weight. Generally, there are three kinds of PLA, poly(D-lactic acid) (PDLA), poly(L-lactic acid) (PLLA), and the racemic blend D,L-PLA (PDLLA), based on different microstructures. PLLA and the racemic blend PDLLA are semicrystalline with slightly different glass transition temperatures, while D-PLA (PDLA) is always amorphous [23]. Degree of crystallization as well as the reactivity of polymer is sensitive to the ratio of $\mathrm{D}$ to L enantiomers used. Different structures of these three PLA materials decide that each kind of PLA has its applicable field. For example, PDLLA is often used in drug delivery system owing to its monophasic structure, but PLLA is more likely to be used where good mechanical behavior is essential. However, pure PLA materials inevitably present much restriction when put into use, such as brittle behavior, poor osteoinduction, and uncontrolled degradation rate. For a long time, many types of chemicals, such as citrate esters [24], and some low-molecular-weight plasticizers such as sorbitol and glycerol have been widely used in this area to plasticize PLA. Plasticizers such as glucose monoesters, poly(ethylene glycol) (PEG), and partial fatty acid esters [25] were also tried to improve the impact resistance and the flexibility of PLA, but the biocompatibility of PLA materials is not that easy to improve so that PLA based nanocomposites appear.

PLA based nanocomposites, which include PLA based copolymers in nanometer size and nanocomposites with PLA or PLA copolymers as matrix and nanofillers as annexing agent, have shown great potential in biomedical field [26]. The small scale effect and surface effect nanomaterials have particularly helped improve the properties of PLA and make PLA based nanocomposites more popular compared with pure PLA materials when it comes to synthetic bone substitute and repair, tissue engineering, and drug delivery system.

Among all the PLA based copolymers, poly(lacticglycolic acid) (PLGA) has attracted the most public attention and has been approved by FDA for clinical uses. It can be obtained from lactide monomer and polyglycolic acid (PGA) by ring-opening polymerization, which nowadays turns out to be the most efficient way to prepare high-molecular-weight polylactic acid as well as PLA based copolymers. Compared with conventional polycondensation, the polymerization efficiency of ring-opening polymerization can be guaranteed and some intended properties of polymers can also be obtained [27]. Other diversified polymers, such as polyethylene oxide [28], polyvinyl acetate [29], and polyethylene glycol [30], can also be polymerized with PLA for specific applications.

Nanocomposites with PLA or PLA copolymers as matrix significantly help improve PLA's properties and overcome its shortcomings. Several studies have been performed using some fillers such as clay minerals, carbon nanotubes, and graphene and its precursor to obtain nanocomposite materials [31-34]. Polymer nanocomposites exhibit apparently improved properties when compared with pure polymers or their traditional composites [35-38]. Pinto et al. [39] discussed the effect of small amounts ( 0.2 to 1 mass\%) of graphene oxide and graphene nanosheets on functional properties of polylactic acid films. Their results showed that yield strength, Young's modulus, and impermeability of resulting nanocomposites were higher than those of pristine PLA. Beside these three nanomaterials, organomontmorillonite and natural nanofibers are also typical annexing agents. Synergy usually exists between different fillers when they are added together into PLA matrix [40]. Fillers mentioned above such as clay minerals, carbon nanotubes, and nanofibers are more frequently used to improve the mechanical properties of PLA materials. In the case of biomaterials, biocompatibility and bioactivity should be paid more attention. In the field of bone substitute and repair, calcium phosphate ceramics such as hydroxyapatite and $\beta$ tricalcium phosphate play important roles owing to their higher biological compatibility. When it comes to tissue engineering, additives such as collagen, graphene oxide, and demineralized bone particle are diffusely investigated in many researches. As for drug delivery system, PLGA nanoparticles attract extensive concern and montmorillonite is also reported to be beneficial in prolonging the drug releasing time (see later in this review).

With the development of manufacturing technology, the shape of PLA based nanocomposites is also tending to be various. Different shapes of foams, meshes, films, fibers, or microspheres are all available. This review will be dedicated to introducing some update research progresses with an eye to the applications of PLA based nanocomposites as biomaterials.

\section{Synthetic Bone Substitute and Repair}

Over the past few decades, the incidence of various bone diseases has been increasing and traffic accidents happen more frequently with the development of human's living standard, inducing a growing need for synthetic bone substitute materials or bone repair materials. Bone of human body has a high chance of being damaged or lost in injuries or just due to pathologic changes. Now the reconstruction of bone has been a major focus point in preclinical research and clinical application, giving rise to the development of materials that help to regenerate bone and repair bone defects [41-43]. Bone defect repair is really common in orthopedic surgeon [44], where synthetic bone substitutes must be used and implanted in human bodies and it is of great importance to find suitable substitutes.

An ideal and suitable bone substitute should possess outstanding biocompatibility and osteoinductive and osteoconductive properties [45]. In previous studies, bioabsorbable polymer devices with nontoxicity have been widely used in orthopedic surgery including fractures repair and bone replacement. Pins, plates, and screws are those frequently used forms of polymer devices in oral, orthopedic, and craniofacial surgeries [46-49]. PLA and PLGA are two promising materials which are widely studied and used to prepare porous scaffolds and repair damaged bones [19, 50, 51]. The superior degradation of PLA materials makes no necessity for second operation and prevents implant removal so that the pain of patients can be alleviated. Plus, using PLA materials helps avoid stress block and reduce the risk of operation failure. However, pure PLA materials lack bone-bonding 


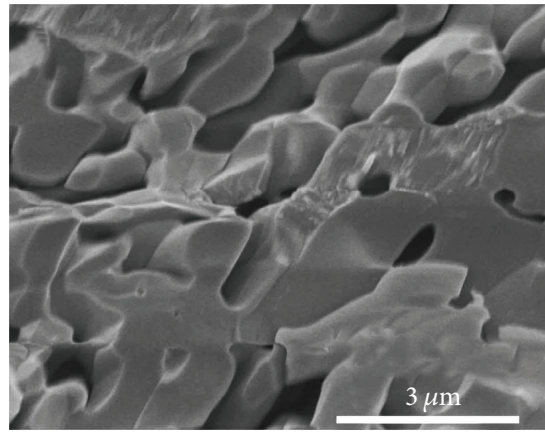

(a)



(d)

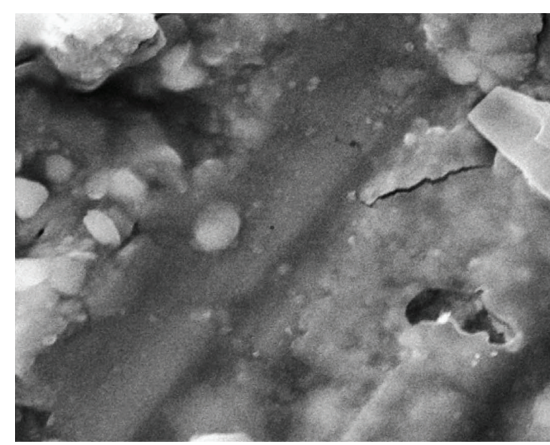

(b)

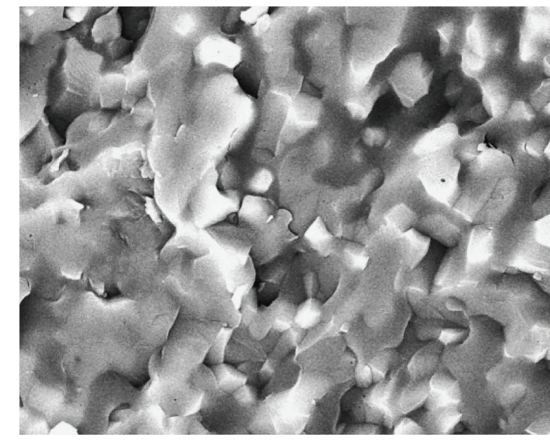

(e)

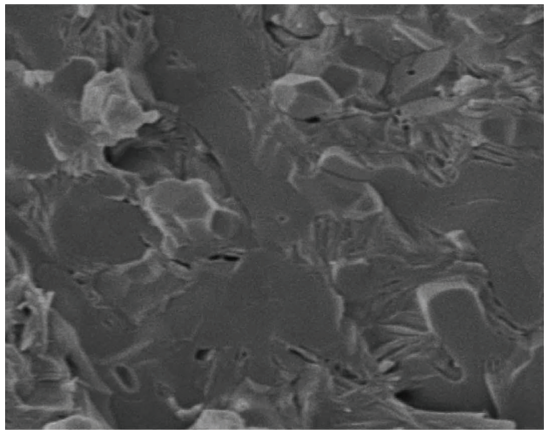

(c)

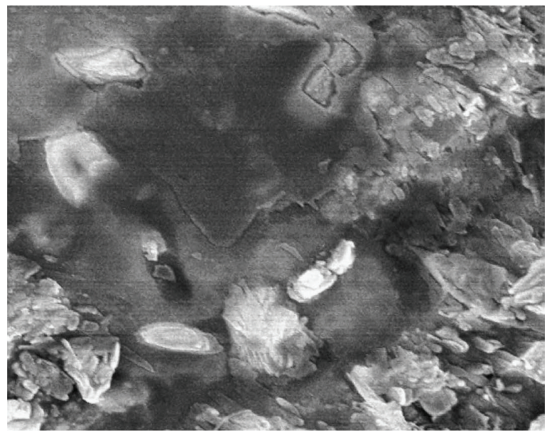

(f)

Figure 1: Cross-sectional scanning electron microscopy images of (a) HAp, (b) PGA/HAp, (c) PLGA20/HAp, (d) PLGA50/HAp, (e) PLGA80/Hap, and (f) PLLA/HAp composites polymerized at $100^{\circ} \mathrm{C}$ for 9 days (originally adapted from [63]).

force and the regeneration efficacy and degradation behavior of PLA are not as good as PLA based nanocomposites.

Schneider et al. [52-54] successfully prepared a flexible nanocomposite with a cotton wool-like appearance through an electrospinning process. Amorphous tricalcium phosphate nanoparticles (TCP) were added to the biodegradable copolymer PLGA (PLGA/TCP60:40). This characteristic of the material with a typical cotton wool-like shape can be adapted in any bone defect due to its superior moldability. Compared with PLGA-treated defects, the closure behavior of PLGA/TCP-treated defects improved a lot in almost all nine New Zealand white rabbits. Moreover, resorption of graft material four weeks after implantation was also reported later [54].

Hydroxyapatite (HAp) is one of the calcium phosphate ceramics that have been largely used as artificial bone materials. The similarity to human bone elements and excellent biocompatibility enable hydroxyapatite to be used as suitable implant in many surgical operations [55-57]. HAp has also been widely added to PLA matrix and HAp-PLLA composites obtained exhibit superior biological performance [58-62]. Takeoka et al. [63] managed to polymerize L-lactide and glycolide in situ and several PLGA/HAp composites with different ratio of L-lactide and glycolide in porous HAp disks were successfully obtained. Scanning electron microscopy result (Figure 1) indicated that porous HAp was completely full of PLGA after polymerization at $100^{\circ} \mathrm{C}$ for 9 days while PLLA/HAp composites were found containing continuous open pores. After $5 \mathrm{~h}$ cultivation of MC3T3-E1 cells,
PLGA20/HAp presented the most adhesion ratio of $38.8 \pm 3.7$, almost twice of PGA/HAp composites, suggesting that these PLGA/HAp composites had suitably bioactive surfaces. After immersion in PBS, the $\mathrm{pH}$ value of PLGA80/HAp was even over 7.0, which was beneficial to relieve the inflammatory reaction that plants may cause after degradation.

Beside hydroxyapatite, bioactive glass particles such as Bioglass 45S5 [64] also have attracted much attention due to the great importance of controlling degradation rate of PLA composites used as bone fixation devices, which can be affected by crystallinity, molecular weight, size, and shape of the specimens. Many researches ascertain that the existence of bioactive glass facilitates the degradation of polymers and there will be an initial sharp weight loss due to the dissolution of the bioglass $[65,66]$. When the bioglass comes into contact with human body fluids, the local environment turns alkaline gradually along with the salting-out of bioglass, just to be able to neutralize lactic acid and slow down the degradation rate of polymers. In general, almost all the studies show a close relationship between bioglass and the degradation of polymer matrix; that is to say, the loss of molecular weight is related not only to autocatalytic degradation, but also to bioglass dissolution itself. Vergnol et al. [67] combined PLLA with Bioglass 45 S5 particles and in vitro cell viability testing together with in vivo experiment on rabbits was conducted. Results suggested that the existence of bioglass in composites really accelerated the degradation of polymer and a bioglass proportion of $30 \mathrm{wt} \%$ seemed to be able to promote bone osseointegration especially during the first month of 


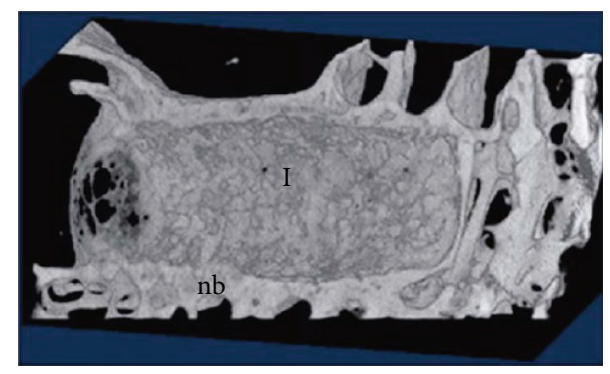

Figure 2: The 3D reconstruction of the bone around a composite C30 implant after 6 months of implantation (with ImageJ software) ( $\mathrm{I}=$ implant; $\mathrm{nb}=$ newly formed bone) (originally adapted from [67]).

implantation. A white line representing the formation of new bone surrounding the implants can be clearly observed on $\mathrm{X}$-ray tomography and 3D picture after one month (Figure 2). All these results indicated that this composite with $30 \mathrm{wt} \%$ of bioglass particles had thus strong potential for health applications.

Bone allograft owns good osteoconduction and osteoinduction, whose chemical components resemble bone autograft, but its clinic application has been limited because of its difficulty of shaping, poor porosity, and bad degradation behavior. Demineralized bone matrix (DBM) emerges in this situation; the collagen and osteoinductive growth factors which it contains really do good for bone regeneration. DBM formulations are various in market, such as granules, powder, gel, putty, and paste, only depending on the manufacturing method. However, the mechanical properties and porosity of $\mathrm{DMB}$ are relatively poor, no matter which formulation [68]. Zhang et al. [45] prepared porous PLA/DBM composite biomaterials by supercritical $\mathrm{CO}_{2}$ technique, which is a new preparation method, especially suitable for the processing of bioactive materials containing growth factors. Results showed that the mechanical properties of composites are significantly improved. Compared with pure PLA and bone autograft, the repairing effect of PLA/DBM composite to bone is better than PLA and is almost the same as bone autograft, reflected from the X-ray result and histological analysis. Finally the feasibility for PLA/DBM to repair bone defects was put forward by the author.

In the field of bone substitute and repair, the degradation rate, degradation products, mechanical property, and bioactivity of the implant materials must be taken into consideration. These properties of PLA or PLGA will be improved with tricalcium phosphate nanoparticles, hydroxyapatite, bioglass, or demineralized bone matrix added to it. The proportion of these fillers also have sensitive influence on the properties of PLA based nanocomposites.

\section{Tissue Engineering}

Tissue engineering, which focuses on the formation and regeneration of tissues and organs, is now an emerging area in human healthcare area. It has facilitated numerous humans due to the long-term dedication to the structure, function, and growth mechanism of biological tissues against the background of cellular biology and bioengineering development. Scaffolds, as the carriers of cell adhesion and growth, play a decisive role in tissue engineering and have been used in many branches, such as bone regeneration [69], blood vessel [70], and neural system [71]. Ideal scaffolds should not only have suitable construction beneficial to cells growing but also have excellent biofunctionality because the behavior of cells can be easily influenced by the local environment, including some biochemical and mechanical cues [72].

PLA materials are widely used as scaffolds due to its good biocompatibility. The different efficacy aligned and random PLLA nano/microfibrous scaffolds have for neural tissue engineering has been compared [71]. Results showed that neural stem cells (NSC) and its neurite outgrowth had tendency to elongate in the direction parallel to PLLA fibers for aligned scaffolds and there seemed to be no relation between cell differentiation rate and fiber arrangement, while nanofibers exhibited better differentiation performance compared with microfibers, indicating the great potential aligned nanofibrous PLLA scaffold has for neural tissue engineering. Many other biomaterials such as collagen and graphene oxide are gradually introduced to polymerize with PLA or PLGA in order to obtain optimized scaffold structures. Qiao et al. [69] blended type I collagen with PDLLA and finally found that when type I collagen occupied a proportion of $40 \%$ in the scaffolds, PDLLA/collagen scaffolds showed greatest stability, cell proliferation, and osteogenic differentiation after five-week cultivation. As is shown in Figures 3(a) and 3(b), PDL60/Col and PDL60/Gel scaffolds have the same size of 500-1000 nm in diameter. However, in Figures 3(c), 3(d), and $3(\mathrm{e})$, the number of cells attached to PDL60/Col scaffolds is obviously greater than those attached to PDL60/Gel scaffolds. Moreover, cells on PDL60/Gel scaffolds are spherical in shape while cells on PDL60/Col scaffolds are flat, which also indicates better cell adhesion property of PDL60/Col scaffolds compared with PDL60/Gel scaffolds.

Shin et al. [72] successfully fabricated hybrid fiber matrices GO-PLGA-Col composed of PLGA and collagen (Col) impregnated with GO via an electrospinning technique. Component analysis suggested a well-proportioned distribution of GO all over the GO-PLGA-Col matrices. The hydrophilicity of the matrices was extensively increased only even though a small amount of Col and GO was added. Results also showed that these hybrid matrices helped induce spontaneous myogenesis which made it the appropriate candidate for skeletal tissue engineering.

Electrospinning process was well utilized in the researches mentioned above $[69,71,72]$ and electrospinning is indeed an effective way to prepare scaffolds due to its numerous superiorities such as mass production capability and high surface areas of scaffolds. However, there are many other methods including solvent casting/particulate leaching [73], phase separation [74], emulsion freeze-drying [75], gas formation [76], and fiber bonding [77]. Ziabari et al. [77] successfully fabricated PLGA scaffolds with demineralized bone particle (DBP) via the solvent casting/salt leaching method. Cell growth and gene expression of smooth muscle cells (SMCs) were upregulated with DBP in PLGA scaffold. 


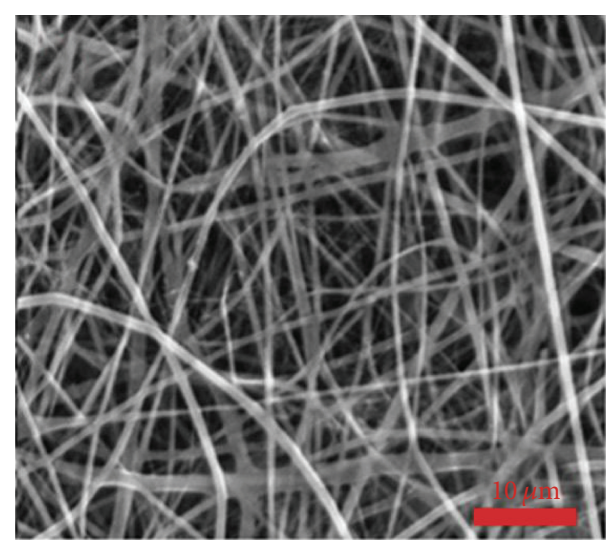

(a)

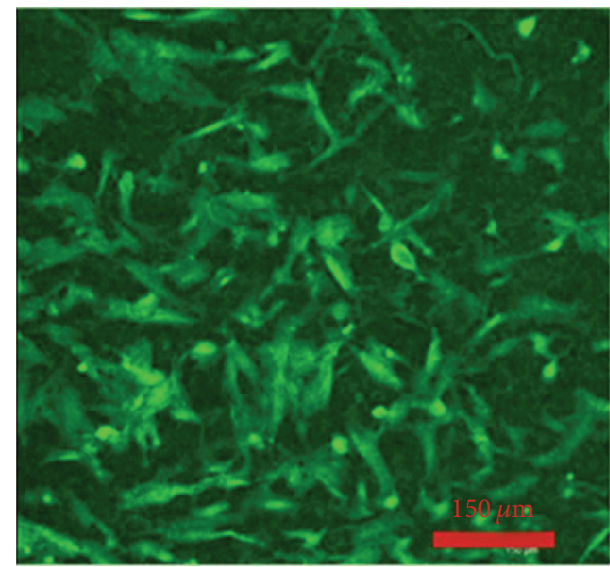

(c)

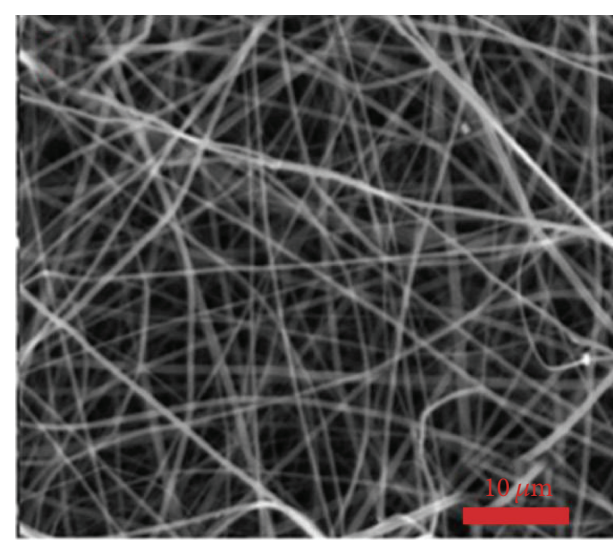

(b)



(d)

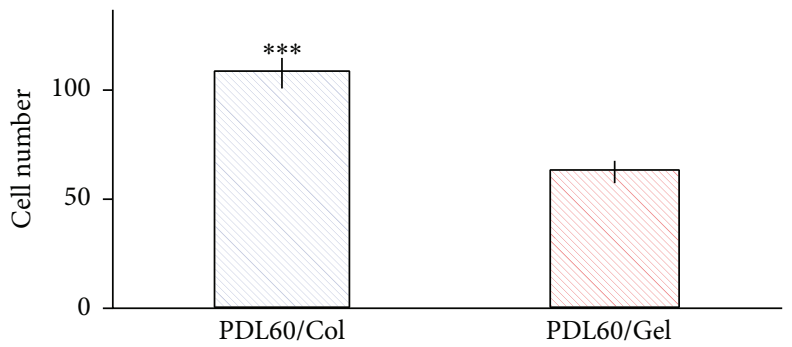

(e)

Figure 3: HBMSCs attachment on the PDL60/Col and PDL60/Gel electrospun scaffolds. (a, b) are SEM images of PDL60/Col scaffolds and PDL60/Gel scaffolds, respectively. (c, d) are maximum projection fluorescence images of PDL60/Col and PDL60/Gel cell-scaffold constructs, respectively. (e) Cell numbers were counted based on the confocal images (originally adapted from [69]). ${ }^{* * *}$ PDL60.

Ardjomandi et al. [78] prepared a series of coatings of $\beta$-tricalcium phosphate scaffolds through dip-and-dry coating and then angularity and topography of the developed scaffolds were analyzed. In the long term, it is really difficult to control and design the pore size and interconnectivity of scaffold $[79,80]$. What is worse, the organic solvents used may cause some damage to cells or tissues [79]. The appearance of a new method called $3 \mathrm{D}$ printing based on computer-aided design (CAD) can perfectly solve this intractable problem and it has led to a revolution in manufacturing industry. Shim et al. [81] recently creatively prepared a resorbable semi-dome-shaped polycaprolactone $(\mathrm{PCL}) / \mathrm{PLGA} / \beta$-TCP membrane through a $3 \mathrm{D}$ printing system (Figure 4), with both rapid degradation rate of PLGA and high elasticity of PCL taken into consideration. In vitro mechanical and cytology test, in vivo preclinical implanting experiment, and a comparison with a titanium membrane were all conducted. When bone regeneration experiment was performed on oral bone defects, results showed the PCL/PLGA/ $\beta$-TCP membrane had almost similar properties to those nonresorbable and commonly used titanium mesh membrane, such as osseointegration and the ability to form 


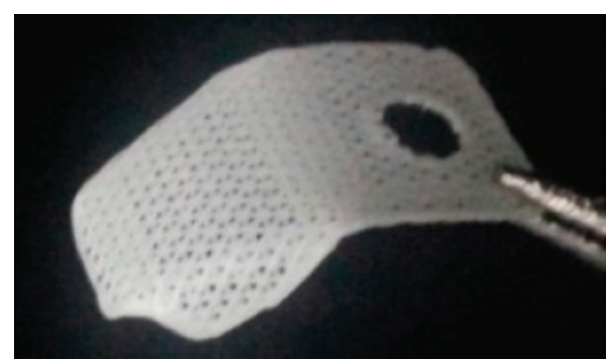

Figure 4: A PCL/PLGA/ $\beta$-TCP membrane produced using 3D printing technology. Pores were triangularly structured and completely interconnected (originally adapted from [81]).

new bone around the implants. This $3 \mathrm{D}$ printing technique coordinating with this biomaterial provided a new choice for tissue engineering field.

Novel ideas and structures of scaffolds are emerging endlessly and have achieved considerable research achievements. Davachi et al. [82] melt-mixed a high-molecularweight PLLA and 30\% encapsulated triclosan with a lowmolecular-weight PLLA (LATC30) in different proportions. Results showed that PLA3 (with 5\% LATC30) was opted to be the most suitable candidate for bone tissue engineering, which was mainly because the encapsulation of triclosan had reduced its negative effect near the tissue environment. Besides, P(LA-co-CL) copolymer with a star shape has attracted public attention. Shafiq et al. [83] recently mixed $\mathrm{P}$ (LA-co-CL) and substance $\mathrm{P}(\mathrm{SP}-)$ conjugated star-shaped $\mathrm{P}$ (LA-co-CL) copolymers in appropriate ratios and then fabricated nonwoven meshes via electrospinning. Meshes containing $\mathrm{P}(\mathrm{LA}-\mathrm{Co}-\mathrm{CL})$ and $\mathrm{SP}$ were then set subcutaneously in Sprague-Dawley rats. Cellularization of P(LAco-CL) as well as SP-containing meshes was revealed when proceeding hematoxylin and eosin staining test. A large amount of mature blood vessels was later observed in SPcontaining meshes compared with their control counterparts, further proving the possibility that these novel scaffolds have to be applied in tissue regeneration of soft tissues.

In general, great efforts have been made to increase cell adhesion and cell proliferation on the surface of scaffolds in the field of tissue engineering. Different kinds of collagen and other additives have also been added to increase the surfactivity of PLA or PLGA. In this field, technologies of tissue regeneration turn out to be mature while the feasibility of PLA based nanocomposites being used in blood vessel and neural system needs to be further demonstrated through plentiful experiments, which might be the new future direction of PLA based nanocomposites as well.

\section{Drug Delivery System}

Conventional drug formulations usually suffer the drawback of uncontrollable therapeutic drug level in human body so that good curative effect cannot be guaranteed. Patients have to take medicine several times a day in order to maintain a certain drug level, which has undesirable side effects and is also a burden mentally. Drug delivery system is therefore a pivotal link in drug therapy [84-86], which aims to maintain a sustained blood drug concentration by delivering the drug to the microenvironment in a good time and at a certain rate gradually, meanwhile avoiding the decomposition of drugs $[87,88]$. More importantly, it can be acted on a targeted area of human body. The primary characteristics of this system include biodegradability, biocompatibility, nontoxicity, prolonged circulation, and a wide payload spectrum of a therapeutic agent [89]. Nowadays, nanoparticles of biodegradable polymers are extensively used to improve the therapeutic effect of various water soluble or water insoluble drugs. The presence of those nanoparticles helps to improve bioavailability, solubility, and retention time of the drugs in human bodies and further bioactive molecules are also expected [90, 91]. All the biodegradable polymer nanoparticles can be approximately divided into two categories, one is nanocapsule and the other is nanosphere [92]. The drug molecules exist inside the polymer or absorbed on the surface.

Polylactic acid (PLA) has been mostly exploited to prepare biodegradable nanoparticles by solvent evaporation, solvent displacement [93], salting-out [94], and solvent diffusion. As a result, these drug carriers represent a marvelous efficacy in the encapsulation of psychotic drugs (savoxepine) [95], restenosis drugs (tyrphostins) [96], hormones (progesterone) [97], oridonin [98], and protein (BSA) [99] as well as enhance the used ratio of drugs and alleviate the damage to liver and kidney. Extra drug delivery may occur due to the looser structure when PLA degrades gradually with the extension of retention time, perfectly compensating the less drug delivery arising from the decrease of total drug dose so that a sustained drug delivery system forms.

Besides single polylactic acid carrier, abundant copolymers of PLA have also been put into research. Sánchez et al. [100] found that polymerized PLA/TCP carrier can release $60 \%$ of the gentamicin in the first week and the retention time can reach 4 weeks. As for developing nanoparticles encapsulating therapeutic drugs in controlled releasing field, PLGA and its various derivatives stand out among all the copolymers and have been the center focus [101103]. Ueng et al. [104, 105] concluded that polymerized poly(DL-lactide co-glycolide) nanosphere is an ideal drugloaded material. Govender et al. [101] incorporated procaine hydrochloride into PLGA nanoparticles by nanoprecipitation and found that drug incorporation efficiency can be adjusted by changing $\mathrm{pH}$ value of aqueous phase, replacing procaine hydrochloride with procaine dihydrate or adding excipients without size to further influence the drug delivery efficiency.

Numerous block copolymers consisting of PLGA alternating with hydrophilic moieties like poly(ethylene oxide) (PEO) or poly(ethyleneglycol) (PEG) [106-108] also have been synthesized. Recently, Khodaverdi et al. [109] managed to prepare thermosensitive PLGA-PEG-PLGA triblock copolymers as in situ gelling matrices and in vitro drug release studies showed that it was molecular weight that decided drug release rate, copolymers concentration, and their microstructures in formulations. The authors also highlighted that PLGA-PEG-PLGA with a lactide-to-glycolide 
ratio of $5: 1$ is the optimal system for long-acting controlled release of naltrexone hydrochloride and vitamin B12.

Other biomedical materials, such as fibrin [110], collagen sponge [111], chitosan [112], and bone matrix gelatin (BMG) [113], are also applied to drug carriers due to their excellent bioabsorbability and degradation behavior. Lal and Datta [114] recently developed montmorillonite- (Mt-) PLGA nanocomposites by w/o/w double emulsion solvent evaporation method as sustained release oral delivery vehicle for atenolol (ATN). For Mt-ATN-PLGA nanocomposites (ATN03 and ATN-05), the release of the drug in simulated gastric fluid in the initial $0.5 \mathrm{~h}$ was $1.6 \%$ and $4 \%$, respectively, far less than $32 \%$ of ATN-PLGA nanoparticles. In addition, cumulative release of Mt-ATN-PLGA nanocomposites reached only $70.4 \%$ and $72.4 \%$, respectively, in $24 \mathrm{~h}$ while cumulative release of ATN-PLGA nanoparticles approached to $100 \%$ over a period of $12 \mathrm{~h}$. Experiments conducted in simulated intestinal fluid also showed the same advantage that MtATN-PLGA nanocomposites had in prolonging the gastric residence time of ATN, further indicating possibility of designing the sustained release formulations with improved bioavailability and patient compliance.

However, it still remains a challenge to prepare and store the drug and when PLGA degrades, the surrounding acid environment has a negative effect on protein stability [115]. Constant degradation results in accumulation of acidic monomers; lactic and glycolic acids may occur inside the drug delivery device after constant degradation; then the $\mathrm{pH}$ value of the microenvironment surrounded may reduce and the encapsulated proteins may get easy to denature [116]. To overcome these drawbacks of PLGA, great efforts and large investigations have to be conducted further.

\section{Conclusion}

Polylactic acid is a degradable and nontoxic polymer, which has been widely used as bone substitute and repair material or used in tissue engineering and drug releasing field. However, the application of pure PLA materials is greatly limited due to the accurate and high requirements for material properties. When evaluating PLA materials used in bone regeneration, degradation rate, degradation products, mechanical property, and bioactivity of the implant materials are decisive. As for tissue engineering, researchers paid more attention to how to increase cell adhesion and proliferation ratio of cells on material surfaces. PLA materials are usually prepared porous when applied in drug delivery system, where it is of great importance to control releasing rate, releasing time, and $\mathrm{pH}$ value of the microenvironment surrounded. Common nanoparticles, such as hydroxyapatite, bioactive glass particles, collagen, and graphene oxide, usually own excellent biocompatibility and other functional properties. Once recombined with PLA or the copolymer of PLA, the nanocomposites are expected to greatly expand the application areas of PLA materials.

\section{Competing Interests}

The authors declare that they have no competing interests.

\section{Acknowledgments}

This work was supported by the Priority Academic Program Development of Jiangsu Higher Education Institutions.

\section{References}

[1] R. Langer and D. A. Tirrell, "Designing materials for biology and medicine," Nature, vol. 428, no. 6982, pp. 487-492, 2004.

[2] L. J. Lee, Z. Yang, M. Rahman et al., "Extracellular mRNA detected by tethered lipoplex nanoparticle biochip for lung adenocarcinoma detection," American Journal of Respiratory \& Critical Care Medicine, vol. 193, no. 12, pp. 1431-1433, 2016.

[3] J. Xie, Z. Yang, C. Zhou, J. Zhu, R. J. Lee, and L. Teng, "Nanotechnology for the delivery of phytochemicals in cancer therapy," Biotechnology Advances, vol. 34, no. 4, pp. 343-353, 2016.

[4] Z. Chen, A. Zhang, J. Hu, X. Wang, and Z. Yang, "Electrospun nanofibers for cancer diagnosis and therapy," Biomaterials Science, vol. 4, no. 6, pp. 922-932, 2016.

[5] Z. Yang, L. Chang, C.-L. Chiang, and L. J. Lee, "Micro-/nanoelectroporation for active gene delivery," Current Pharmaceutical Design, vol. 21, no. 42, pp. 6081-6088, 2015.

[6] C. Zhou, Z. Yang, and L. Teng, "Nanomedicine based on nucleic acids: pharmacokinetic and pharmacodynamic perspectives," Current Pharmaceutical Biotechnology, vol. 15, no. 9, pp. 829838, 2015.

[7] Z. Yang, B. Yu, J. Zhu et al., "A microfluidic method to synthesize transferrin-lipid nanoparticles loaded with siRNA LOR-1284 for therapy of acute myeloid leukemia," Nanoscale, vol. 6, no. 16, pp. 9742-9751, 2014

[8] Y. Wen, W. Liu, C. Bagia et al., "Antibody-functionalized peptidic membranes for neutralization of allogeneic skin antigenpresenting cells," Acta Biomaterialia, vol. 10, no. 11, pp. 47594767, 2014.

[9] Y. Wen, H. R. Kolonich, K. M. Kruszewski, N. Giannoukakis, E. S. Gawalt, and W. S. Meng, "Retaining antibodies in tumors with a self-assembling injectable system," Molecular Pharmaceutics, vol. 10, no. 3, pp. 1035-1044, 2013.

[10] W. Liu, M. J. Saunders, C. Bagia et al., "Local retention of antibodies in vivo with an injectable film embedded with a fluorogen-activating protein," Journal of Controlled Release, vol. 230, pp. 1-12, 2016.

[11] L. Zhang, X. Gong, Y. Bao et al., "Electrospun nanofibrous membranes surface-decorated with silver nanoparticles as flexible and active/sensitive substrates for surface-enhanced Raman scattering," Langmuir, vol. 28, no. 40, pp. 14433-14440, 2012.

[12] C. Holderegger, P. R. Schmidlin, F. E. Weber, and D. Mohn, "Preclinical in vivo performance of novel biodegradable, electrospun poly(lactic acid) and poly(lactic-co-glycolic acid) nanocomposites: a review," Materials, vol. 8, no. 8, pp. 49124931, 2015.

[13] J. Xie, L. Teng, Z. Yang et al., "A polyethylenimine-linoleic acid conjugate for antisense oligonucleotide delivery," BioMed Research International, vol. 2013, Article ID 710502, 7 pages, 2013.

[14] B. Yu, X. Wang, C. Zhou et al., "Insight into mechanisms of cellular uptake of lipid nanoparticles and intracellular release of small RNAs," Pharmaceutical Research, vol. 31, no. 10, pp. 2685$2695,2014$. 
[15] Z. Chen, M. Cong, J. Hu, Z. Yang, and Z. Chen, "Preparation of functionalized $\mathrm{TiO}_{2}$ nanotube arrays and their applications," Science of Advanced Materials, vol. 8, no. 6, pp. 1231-1241, 2016.

[16] X. Gong, "Controlling surface properties of polyelectrolyte multilayers by assembly $\mathrm{pH}$," Physical Chemistry Chemical Physics, vol. 15, no. 25, pp. 10459-10465, 2013.

[17] X. Gong, "Facile formation of nanoparticle patterns by water induced flow of a polymer thin film," RSC Advances, vol. 4, no. 97, pp. 54494-54499, 2014.

[18] N. A. Peppas and R. Langer, "New challenges in biomaterials," Science, vol. 263, no. 5154, pp. 1715-1720, 1994.

[19] K. Rezwan, Q. Z. Chen, J. J. Blaker, and A. R. Boccaccini, "Biodegradable and bioactive porous polymer/inorganic composite scaffolds for bone tissue engineering," Biomaterials, vol. 27, no. 18, pp. 3413-3431, 2006.

[20] A. Araújo, G. Botelho, M. Oliveira, and A. V. Machado, "Influence of clay organic modifier on the thermal-stability of PLA based nanocomposites," Applied Clay Science, vol. 88-89, pp. 144-150, 2014.

[21] T. Kuang, L. Chang, F. Chen, Y. Sheng, D. Fu, and X. Peng, "Facile preparation of lightweight high-strength biodegradable polymer/multi-walled carbon nanotubes nanocomposite foams for electromagnetic interference shielding," Carbon, vol. 105, pp. 305-313, 2016.

[22] T. R. Kuang, H. Y. Mi, D. J. Fu et al., "Fabrication of poly(lactic acid)/graphene oxide foams with highly oriented and elongated cell structure via unidirectional foaming using supercritical carbon dioxide," Industrial \& Engineering Chemistry Research, vol. 54, no. 2, pp. 758-768, 2015.

[23] M. Treiser, S. Abramson, R. Langer, and J. Kohn, "Degradable and resorbable biomaterials," in Biomaterials Science, B. D. Ratner, A. S. Hoffman, F. J. Schoen, and J. E. Lemons, Eds., chapter I.2.6, pp. 179-195, 3rd edition, 2013.

[24] O. Martin and L. Avérous, "Poly(lactic acid): plasticization and properties of biodegradable multiphase systems," Polymer, vol. 42, no. 14, pp. 6209-6219, 2001.

[25] P. Gupta, K. Vermani, and S. Garg, "Hydrogels: from controlled release to $\mathrm{pH}$-responsive drug delivery," Drug Discovery Today, vol. 7, no. 10, pp. 569-579, 2002.

[26] B. Y. Chen, Y. S. Wang, H. Y. Mi et al., "Effect of poly(ethylene glycol) on the properties and foaming behavior of macroporous poly(lactic acid)/sodium chloride scaffold," Journal of Applied Polymer Science, vol. 131, no. 23, pp. 205-212, 2014.

[27] K. M. Nampoothiri, N. R. Nair, and R. P. John, "An overview of the recent developments in polylactide (PLA) research," Bioresource Technology, vol. 101, no. 22, pp. 8493-8501, 2010.

[28] A. J. Nijenhuis, E. Colstee, D. W. Grijpma, and A. J. Pennings, "High molecular weight poly(L-lactide) and poly(ethylene oxide) blends: thermal characterization and physical properties," Polymer, vol. 37, no. 26, pp. 5849-5857, 1996.

[29] A. M. Gajria, V. Davé, R. A. Gross, and S. P. McCarthy, "Miscibility and biodegradability of blends of poly(lactic acid) and poly(vinyl acetate)," Polymer, vol. 37, no. 3, pp. 437-444, 1996.

[30] M. Sheth, R. A. Kumar, V. Davé, R. A. Gross, and S. P. McCarthy, "Biodegradable polymer blends of poly(lactic acid) and poly(ethylene glycol)," Journal of Applied Polymer Science, vol. 66, no. 8, pp. 1495-1505, 1997.

[31] M. Keshtkar, M. Nofar, C. B. Park, and P. J. Carreau, "Extruded PLA/clay nanocomposite foams blown with supercritical $\mathrm{CO}_{2}$," Polymer, vol. 55, no. 16, pp. 4077-4090, 2014.
[32] F. Mai, Y. Habibi, J.-M. Raquez et al., "Poly(lactic acid)/carbon nanotube nanocomposites with integrated degradation sensing," Polymer, vol. 54, no. 25, pp. 6818-6823, 2013.

[33] E. Narimissa, R. K. Gupta, N. Kao, H. J. Choi, M. Jollands, and S. N. Bhattacharya, "Melt rheological investigation of polylactidenanographite platelets biopolymer composites," Polymer Engineering \& Science, vol. 54, no. 1, pp. 175-188, 2014.

[34] B. Wang, T. Wan, and W. Zeng, "Rheological and thermal properties of polylactide/organic montmorillonite nanocomposites," Journal of Applied Polymer Science, vol. 125, no. 2, pp. E364E371, 2012.

[35] C. Miao and W. Y. Hamad, "Cellulose reinforced polymer composites and nanocomposites: a critical review," Cellulose, vol. 20, no. 5, pp. 2221-2262, 2013.

[36] M. Luddee, S. Pivsa-Art, S. Sirisansaneeyakul, and C. Pechyen, "Particle size of ground bacterial cellulose affecting mechanical, thermal, and moisture barrier properties of PLA/BC biocomposites," Energy Procedia, vol. 56, pp. 211-218, 2014.

[37] K. Issaadi, A. Habi, Y. Grohens, and I. Pillin, "Effect of the montmorillonite intercalant and anhydride maleic grafting on polylactic acid structure and properties," Applied Clay Science, vol. 107, pp. 62-69, 2015.

[38] L. Zhang, Y. Li, H. Wang, Y. Qiao, J. Chen, and S. Cao, "Strong and ductile poly(lactic acid) nanocomposite films reinforced with alkylated graphene nanosheets," Chemical Engineering Journal, vol. 264, pp. 538-546, 2015.

[39] A. M. Pinto, J. Cabral, D. A. P. Tanaka, A. M. Mendes, and F. D. Magalhães, "Effect of incorporation of graphene oxide and graphene nanoplatelets on mechanical and gas permeability properties of poly(lactic acid) films," Polymer International, vol. 62, no. 1, pp. 33-40, 2013.

[40] B. S. Bouakaz, I. Pillin, A. Habi, and Y. Grohens, "Synergy between fillers in organomontmorillonite/graphene-PLA nanocomposites," Applied Clay Science, vol. 116-117, pp. 69-77, 2015.

[41] R. Dimitriou, E. Jones, D. McGonagle, and P. V. Giannoudis, "Bone regeneration: current concepts and future directions," BMC Medicine, vol. 9, article 66, 2011.

[42] M. L. Ferrone and C. P. Raut, "Modern surgical therapy: limb salvage and the role of amputation for extremity soft-tissue sarcomas," Surgical Oncology Clinics of North America, vol. 21, no. 2, pp. 201-213, 2012.

[43] G. Martou and O. M. Antonyshyn, "Advances in surgical approaches to the upper facial skeleton," Current Opinion in Otolaryngology \& Head and Neck Surgery, vol. 19, no. 4, pp. 242247, 2011.

[44] D. R. Sidell, T. Aghaloo, S. Tetradis et al., "Composite mandibulectomy: a novel animal model," OtolaryngologyHead and Neck Surgery, vol. 146, no. 6, pp. 932-937, 2012.

[45] Y. Zhang, J. Wang, J. Wang et al., "Preparation of porous PLA/DBM composite biomaterials and experimental research of repair rabbit radius segmental bone defect," Cell and Tissue Banking, vol. 16, no. 4, pp. 615-622, 2015.

[46] L. E. Claes, A. A. Ignatius, K. E. Rehm, and C. Scholz, "New bioresorbable pin for the reduction of small bony fragments: design, mechanical properties and in vitro degradation," Biomaterials, vol. 17, no. 16, pp. 1621-1626, 1996.

[47] G. Schwach and M. Vert, "In vitro and in vivo degradation of lactic acid-based interference screws used in cruciate ligament reconstruction," International Journal of Biological Macromolecules, vol. 25, no. 1-3, pp. 283-291, 1999. 
[48] R. Suuronen, "Comparison of absorbable self-reinforced polyL-lactide screws and metallic screws in the fixation of mandibular condyle osteotomies: an experimental study in sheep," Journal of Oral and Maxillofacial Surgery, vol. 49, no. 9, pp. 989995, 1991.

[49] A. R. Santos Jr., Bioresorbable Polymers for Tissue Engineering, INTECH Open Access Publisher, 2010.

[50] R. P. F. Lanao, A. M. Jonker, J. G. C. Wolke, J. A. Jansen, J. C. M. van Hest, and S. C. G. Leeuwenburgh, "Physicochemical properties and applications of poly(lactic-co-glycolic acid) for use in bone regeneration," Tissue Engineering Part B: Reviews, vol. 19, no. 4, pp. 380-390, 2013.

[51] J. Song, J. Xie, C. Li et al., "Near infrared spectroscopic (NIRS) analysis of drug-loading rate and particle size of risperidone microspheres by improved chemometric model," International Journal of Pharmaceutics, vol. 472, no. 1-2, pp. 296-303, 2014.

[52] O. D. Schneider, S. Loher, T. J. Brunner et al., "Cotton wool-like nanocomposite biomaterials prepared by electrospinning: in vitro bioactivity and osteogenic differentiation of human mesenchymal stem cells," Journal of Biomedical Materials Research Part B: Applied Biomaterials, vol. 84, no. 2, pp. 350-362, 2008.

[53] O. D. Schneider, D. Mohn, R. Fuhrer et al., "Biocompatibility and bone formation of flexible, cotton wool-like PLGA/calcium phosphate nanocomposites in sheep," The Open Orthopaedics Journal, vol. 5, pp. 63-71, 2011.

[54] O. D. Schneider, F. Weber, T. J. Brunner et al., "In vivo and in vitro evaluation of flexible, cottonwool-like nanocomposites as bone substitute material for complex defects," Acta Biomaterialia, vol. 5, no. 5, pp. 1775-1784, 2009.

[55] R. W. Bucholz, A. Carlton, and R. E. Holmes, "Hydroxyapatite and tricalcium phosphate bone graft substitutes," The Orthopedic Clinics of North America, vol. 18, no. 2, pp. 323-334, 1987.

[56] C. A. Van Blitterswijk, J. J. Grote, W. Kuijpers, W. T. Daems, and K. De Groot, "Macropore tissue ingrowth: a quantitative and qualitative study on hydroxyapatite ceramic," Biomaterials, vol. 7, no. 2, pp. 137-143, 1986.

[57] W. Suchanek and M. Yoshimura, "Processing and properties of hydroxyapatite-based biomaterials for use as hard tissue replacement implants," Journal of Materials Research, vol. 13, no. 1, pp. 94-117, 1998.

[58] S. Hasegawa, S. Ishii, J. Tamura et al., "A 5-7 year in vivo study of high-strength hydroxyapatite/poly(L-lactide) composite rods for the internal fixation of bone fractures," Biomaterials, vol. 27, no. 8, pp. 1327-1332, 2006.

[59] C. C. P. M. Verheyen, C. P. A. T. Klein, J. M. A. De BlieckHogervorst, J. G. C. Wolke, C. A. Van Blitterswijn, and K. De Groot, "Evaluation of hydroxylapatite/poly(L-lactide) composites: physico-chemical properties," Journal of Materials Science: Materials in Medicine, vol. 4, no. 1, pp. 58-65, 1993.

[60] T. Furukawa, Y. Matsusue, T. Yasunaga et al., "Histomorphometric study on high-strength hydroxyapatite/poly(L-lactide) composite rods for internal fixation of bone fractures," Journal of Biomedical Materials Research, vol. 50, no. 3, pp. 410-419, 2000.

[61] T. Yasunaga, Y. Matsusue, T. Furukawa, Y. Shikinami, M. Okuno, and T. Nakamura, "Bonding behavior of ultrahigh strength unsintered hydroxyapatite particles/poly(L-lactide) composites to surface of tibial cortex in rabbits," Journal of Biomedical Materials Research, vol. 47, no. 3, pp. 412-419, 1999.

[62] S. Ishii, J. Tamura, T. Furukawa et al., "Long-term study of highstrength hydroxyapatite/poly(L-lactide) composite rods for the internal fixation of bone fractures: a 2-4-year follow-up study in rabbits," Journal of Biomedical Materials Research Part B: Applied Biomaterials, vol. 66, no. 2, pp. 539-547, 2003.

[63] Y. Takeoka, M. Hayashi, N. Sugiyama, M. Yoshizawa-Fujita, M. Aizawa, and M. Rikukawa, "In situ preparation of poly(l-lactic acid-co-glycolic acid)/hydroxyapatite composites as artificial bone materials," Polymer Journal, vol. 47, no. 2, pp. 164-170, 2015.

[64] W. Lu, K. Ji, J. Kirkham et al., "Bone tissue engineering by using a combination of polymer/Bioglass composites with human adipose-derived stem cells," Cell and Tissue Research, vol. 356, no. 1, pp. 97-107, 2014.

[65] H. Li and J. Chang, "pH-compensation effect of bioactive inorganic fillers on the degradation of PLGA," Composites Science and Technology, vol. 65, no. 14, pp. 2226-2232, 2005.

[66] V. Maquet, A. R. Boccaccini, L. Pravata, I. Notingher, and R. Jérôme, "Preparation, characterization, and in vitro degradation of bioresorbable and bioactive composites based on Bioglass-filled polylactide foams," Journal of Biomedical Materials Research-Part A, vol. 66, no. 2, pp. 335-346, 2003.

[67] G. Vergnol, N. Ginsac, P. Rivory et al., "In vitro and in vivo evaluation of a polylactic acid-bioactive glass composite for bone fixation devices," Journal of Biomedical Materials Research Part B: Applied Biomaterials, vol. 104, no. 1, pp. 180-191, 2016.

[68] N. Bakhshalian, H. Nowzari, K. M. Ahn, and B. H. Arjmandi, "Demineralized dentin matrix and bone graft: a review of literature," The Journal of the Western Society of Periodontology/Periodontal Abstracts, vol. 62, no. 2, pp. 35-38, 2014.

[69] X. Qiao, S. J. Russell, X. Yang, G. Tronci, and D. J. Wood, "Compositional and in vitro evaluation of nonwoven type I collagen/poly-dl-lactic acid scaffolds for bone regeneration," Journal of Functional Biomaterials, vol. 6, no. 3, pp. 667-686, 2015.

[70] H. Jo, M. Hong, J. B. Shim et al., "The role of demineralized bone particle in a PLGA scaffold designed to create a media equivalent for a tissue engineered blood vessel," Macromolecular Research, vol. 23, no. 11, pp. 986-993, 2015.

[71] F. Yang, R. Murugan, S. Wang, and S. Ramakrishna, "Electrospinning of nano/micro scale poly(l-lactic acid) aligned fibers and their potential in neural tissue engineering," Biomaterials, vol. 26, no. 15, pp. 2603-2610, 2005.

[72] Y. C. Shin, J. H. Lee, L. Jin et al., "Stimulated myoblast differentiation on graphene oxide-impregnated PLGA-collagen hybrid fibre matrices," Journal of Nanobiotechnology, vol. 13, article 21, 2015.

[73] A. G. Mikos, A. J. Thorsen, L. A. Czerwonka et al., "Preparation and characterization of poly(L-lactic acid) foams," Polymer, vol. 35, no. 5, pp. 1068-1077, 1994.

[74] M. Shin, H. Abukawa, M. J. Troulis, and J. P. Vacanti, "Development of a biodegradable scaffold with interconnected pores by heat fusion and its application to bone tissue engineering," Journal of Biomedical Materials Research-Part A, vol. 84, no. 3, pp. 702-709, 2008.

[75] Y.-Y. Hsu, J. D. Gresser, D. J. Trantolo, C. M. Lyons, P. R. J. Gangadharam, and D. L. Wise, "Effect of polymer foam morphology and density on kinetics of in vitro controlled release of isoniazid from compressed foam matrices," Journal of Biomedical Materials Research, vol. 35, no. 1, pp. 107-116, 1997.

[76] D. J. Mooney, D. F. Baldwin, N. P. Suh, J. P. Vacanti, and R. Langer, "Novel approach to fabricate porous sponges of poly(D,L-lactic-co-glycolic acid) without the use of organic solvents," Biomaterials, vol. 17, no. 14, pp. 1417-1422, 1996. 
[77] M. Ziabari, V. Mottaghitalab, and A. K. Haghi, "A new approach for optimization of electrospun nanofiber formation process," Korean Journal of Chemical Engineering, vol. 27, no. 1, pp. 340354, 2010.

[78] N. Ardjomandi, A. Henrich, J. Huth et al., "Coating of $\beta$-tricalcium phosphate scaffolds-a comparison between graphene oxide and poly-lactic-co-glycolic acid," Biomedical Materials, vol. 10, no. 4, Article ID 45018, 2015.

[79] H. Haugen, J. Will, W. Fuchs, and E. Wintermantel, "A novel processing method for injection-molded polyether-urethane scaffolds. Part 1: processing," Journal of Biomedical Materials Research Part B: Applied Biomaterials, vol. 77, no. 1, pp. 65-72, 2006.

[80] J. Y. Kim, E. K. Park, S.-Y. Kim, J.-W. Shin, and D.-W. Cho, "Fabrication of a SFF-based three-dimensional scaffold using a precision deposition system in tissue engineering," Journal of Micromechanics and Microengineering, vol. 18, no. 5, Article ID 055027, 2008.

[81] J.-H. Shim, J.-Y. Won, S.-J. Sung et al., "Comparative efficacies of a 3D-printed PCL/PLGA/ $\beta$-TCP membrane and a titanium membrane for guided bone regeneration in beagle dogs," Polymers, vol. 7, no. 10, pp. 2061-2077, 2015.

[82] S. M. Davachi, B. Kaffashi, A. Zamanian, B. Torabinejad, and Z. Ziaeirad, "Investigating composite systems based on poly 1-lactide and poly 1-lactide/triclosan nanoparticles for tissue engineering and medical applications," Materials Science and Engineering C, vol. 58, pp. 294-309, 2016.

[83] M. Shafiq, Y. Jung, and S. H. Kim, "Stem cell recruitment, angiogenesis, and tissue regeneration in substance $\mathrm{P}$-conjugated poly(l-lactide-co- $\varepsilon$-caprolactone) nonwoven meshes," Journal of Biomedical Materials Research Part A, vol. 103, no. 8, pp. 26732688, 2015.

[84] Z. Yu, B. Yan, L. Gao et al., "Targeted delivery of bleomycin: a comprehensive anticancer review," Current Cancer Drug Targets, vol. 16, no. 6, pp. 509-521, 2016.

[85] Z. Yu, Z. Cai, Q. Chen et al., "Engineering $\beta$-sheet peptide assemblies for biomedical applications," Biomaterials Science, vol. 4, no. 3, pp. 365-374, 2015.

[86] Z. Yu, Q. Xu, C. Dong et al., "Self-assembling peptide nanofibrous hydrogel as a versatile drug delivery platform," Current Pharmaceutical Design, vol. 21, no. 29, pp. 4342-4354, 2015.

[87] L. Cai, X. Wang, W. Wang et al., "Peptide ligand and PEGmediated long-circulating liposome targeted to FGFR overexpressing tumor in vivo," International Journal of Nanomedicine, vol. 7, pp. 4499-4510, 2012.

[88] H. Gao, Q. Zhang, Z. Yu, and Q. He, "Cell-penetrating peptidebased intelligent liposomal systems for enhanced drug delivery," Current Pharmaceutical Biotechnology, vol. 15, no. 3, pp. 210-219, 2014.

[89] F. Masood, "Polymeric nanoparticles for targeted drug delivery system for cancer therapy," Materials Science and Engineering $C$, vol. 60 , pp. 569-578, 2016.

[90] H. Devalpally, D. Shenoy, S. Little, R. Langer, and M. Amiji, "Poly(ethylene oxide)-modified poly(beta-amino ester) nanoparticles as a $\mathrm{pH}$-sensitive system for tumor-targeted delivery of hydrophobic drugs: part 3. Therapeutic efficacy and safety studies in ovarian cancer xenograft model," Cancer Chemotherapy and Pharmacology, vol. 59, no. 4, pp. 477-484, 2007.
[91] L. L. Cai, N. Qiu, M. L. Xiang et al., "Improving aqueous solubility and antitumor effects by nanosized gambogic acid$\mathrm{mPEG}_{2000}$ micelles," International Journal of Nanomedicine, vol. 9, no. 1, pp. 243-255, 2013.

[92] A. Kumari, S. K. Yadav, and S. C. Yadav, "Biodegradable polymeric nanoparticles based drug delivery systems," Colloids and Surfaces B: Biointerfaces, vol. 75, no. 1, pp. 1-18, 2010.

[93] H. Fessi, F. Puisieux, J. P. Devissaguet, N. Ammoury, and S. Benita, "Nanocapsule formation by interfacial polymer deposition following solvent displacement," International Journal of Pharmaceutics, vol. 55, no. 1, pp. R1-R4, 1989.

[94] C. P. Reis, R. J. Neufeld, A. J. Ribeiro, and F. Veiga, "Nanoencapsulation I. Methods for preparation of drug-loaded polymeric nanoparticles," Nanomedicine: Nanotechnology, Biology, and Medicine, vol. 2, no. 1, pp. 8-21, 2006.

[95] J.-C. Leroux, E. Allémann, F. De Jaeghere, E. Doelker, and R. Gurny, "Biodegradable nanoparticles-from sustained release formulations to improved site specific drug delivery," Journal of Controlled Release, vol. 39, no. 2-3, pp. 339-350, 1996.

[96] I. Fishbein, M. Chorny, L. Rabinovich, S. Banai, I. Gati, and G. Golomb, "Nanoparticulate delivery system of a tyrphostin for the treatment of restenosis," Journal of Controlled Release, vol. 65, no. 1-2, pp. 221-229, 2000.

[97] J. Matsumoto, Y. Nakada, K. Sakurai, T. Nakamura, and Y. Takahashi, "Preparation of nanoparticles consisted of poly $(\mathrm{L}-$ lactide)-poly(ethylene glycol)-poly(L-lactide) and their evaluation in vitro," International Journal of Pharmaceutics, vol. 185, no. 1, pp. 93-101, 1999.

[98] J. Xing, D. Zhang, and T. Tan, "Studies on the oridoninloaded poly(D,L-lactic acid) nanoparticles in vitro and in vivo," International Journal of Biological Macromolecules, vol. 40, no. 2, pp. 153-158, 2007.

[99] H. Gao, Y. N. Wang, Y. G. Fan, and J. B. Ma, "Synthesis of a biodegradable tadpole-shaped polymer via the coupling reaction of polylactide onto mono(6-(2-aminoethyl)amino-6deoxy)- $\beta$-cyclodextrin and its properties as the new carrier of protein delivery system," Journal of Controlled Release, vol. 107, no. 1, pp. 158-173, 2005.

[100] E. Sánchez, M. Baro, I. Soriano, A. Perera, and C. Évora, "In vivo-in vitro study of biodegradable and osteointegrable gentamicin bone implants," European Journal of Pharmaceutics and Biopharmaceutics, vol. 52, no. 2, pp. 151-158, 2001.

[101] T. Govender, S. Stolnik, M. C. Garnett, L. Illum, and S. S. Davis, "PLGA nanoparticles prepared by nanoprecipitation: drug loading and release studies of a water soluble drug," Journal of Controlled Release, vol. 57, no. 2, pp. 171-185, 1999.

[102] D.-H. Kim and D. C. Martin, "Sustained release of dexamethasone from hydrophilic matrices using PLGA nanoparticles for neural drug delivery," Biomaterials, vol. 27, no. 15, pp. 3031-3037, 2006.

[103] U. Bilati, E. Allémann, and E. Doelker, "Poly(D,L-lactideco-glycolide) protein-loaded nanoparticles prepared by the double emulsion method-processing and formulation issues for enhanced entrapment efficiency," Journal of Microencapsulation, vol. 22, no. 2, pp. 205-214, 2005.

[104] S. W. N. Ueng, L.-J. Yuan, N. Lee et al., "In vivo study of hot compressing molded 50:50 poly (DL-lactide-co-glycolide) antibiotic beads in rabbits," Journal of Orthopaedic Research, vol. 20, no. 4, pp. 654-661, 2002.

[105] H. Song, W. Li, R. Qi et al., "Delivering a photosensitive transplatin prodrug to overcome cisplatin drug resistance," Chemical Communications, vol. 51, no. 57, pp. 11493-11495, 2015. 
[106] H. Otsuka, Y. Nagasaki, and K. Kataoka, "PEGylated nanoparticles for biological and pharmaceutical applications," Advanced Drug Delivery Reviews, vol. 55, no. 3, pp. 403-419, 2003.

[107] T. Kissel, Y. Li, and F. Unger, "ABA-triblock copolymers from biodegradable polyester A-blocks and hydrophilic poly(ethylene oxide) B-blocks as a candidate for in situ forming hydrogel delivery systems for proteins," Advanced Drug Delivery Reviews, vol. 54, no. 1, pp. 99-134, 2002.

[108] S. Fischer, E. Uetz-von Allmen, Y. Waeckerle-Men, M. Groettrup, H. P. Merkle, and B. Gander, "The preservation of phenotype and functionality of dendritic cells upon phagocytosis of polyelectrolyte-coated PLGA microparticles," Biomaterials, vol. 28, no. 6, pp. 994-1004, 2007.

[109] E. Khodaverdi, F. S. M. Tekie, S. A. Mohajeri, F. Ganji, G. Zohuri, and F. Hadizadeh, "Preparation and investigation of sustained drug delivery systems using an injectable, thermosensitive, in situ forming hydrogel composed of PLGA-PEG-PLGA," AAPS PharmSciTech, vol. 13, no. 2, pp. 590-600, 2012.

[110] S. Meyenburg, H. Lilie, S. Panzner, and R. Rudolph, "Fibrin encapsulated liposomes as protein delivery system: studies on the in vitro release behavior," Journal of Controlled Release, vol. 69, no. 1, pp. 159-168, 2000.

[111] C. Yao, P. Yao, H. Wu, and Z. Zha, "Acceleration of wound healing in traumatic ulcers by absorbable collagen sponge containing recombinant basic fibroblast growth factor," Biomedical Materials, vol. 1, no. 1, pp. 33-37, 2006.

[112] J. J. Wang, W. Z. Zhao, Z. X. Ren et al., "Recent advances of chitosan nanoparticles as drug carriers," International Journal of Nanomedicine, vol. 6, pp. 765-774, 2011.

[113] V. K. Vishvakarma, K. Kumari, R. Patel, P. Singh, G. K. Mehrotra, and R. Chandra, "Gelatin Nanocomposites (GNCs): an efficient drug delivery system," in Biomedical Applications of Natural Proteins, D. Kumar and R. R. Kundapur, Eds., SpringerBriefs in Biochemistry and Molecular Biology, pp. 129148, Springer, Berlin, Germany, 2015.

[114] S. Lal and M. Datta, "In vitro prolonged gastric residence and sustained release of atenolol using novel clay polymer nanocomposite," Applied Clay Science, vol. 114, pp. 412-421, 2015.

[115] R. C. Mundargi, V. R. Babu, V. Rangaswamy, P. Patel, and T. M. Aminabhavi, "Nano/micro technologies for delivering macromolecular therapeutics using poly(D,L-lactide-coglycolide) and its derivatives," Journal of Controlled Release, vol. 125, no. 3, pp. 193-209, 2008.

[116] B. Bittner, B. Ronneberger, R. Zange, C. Volland, J. M. Anderson, and T. Kissel, "Bovine serum albumin loaded poly(lactideco-glycolide) microspheres: The influence of polymer purity on particle characteristics," Journal of Microencapsulation, vol. 15, no. 4, pp. 495-514, 1998. 

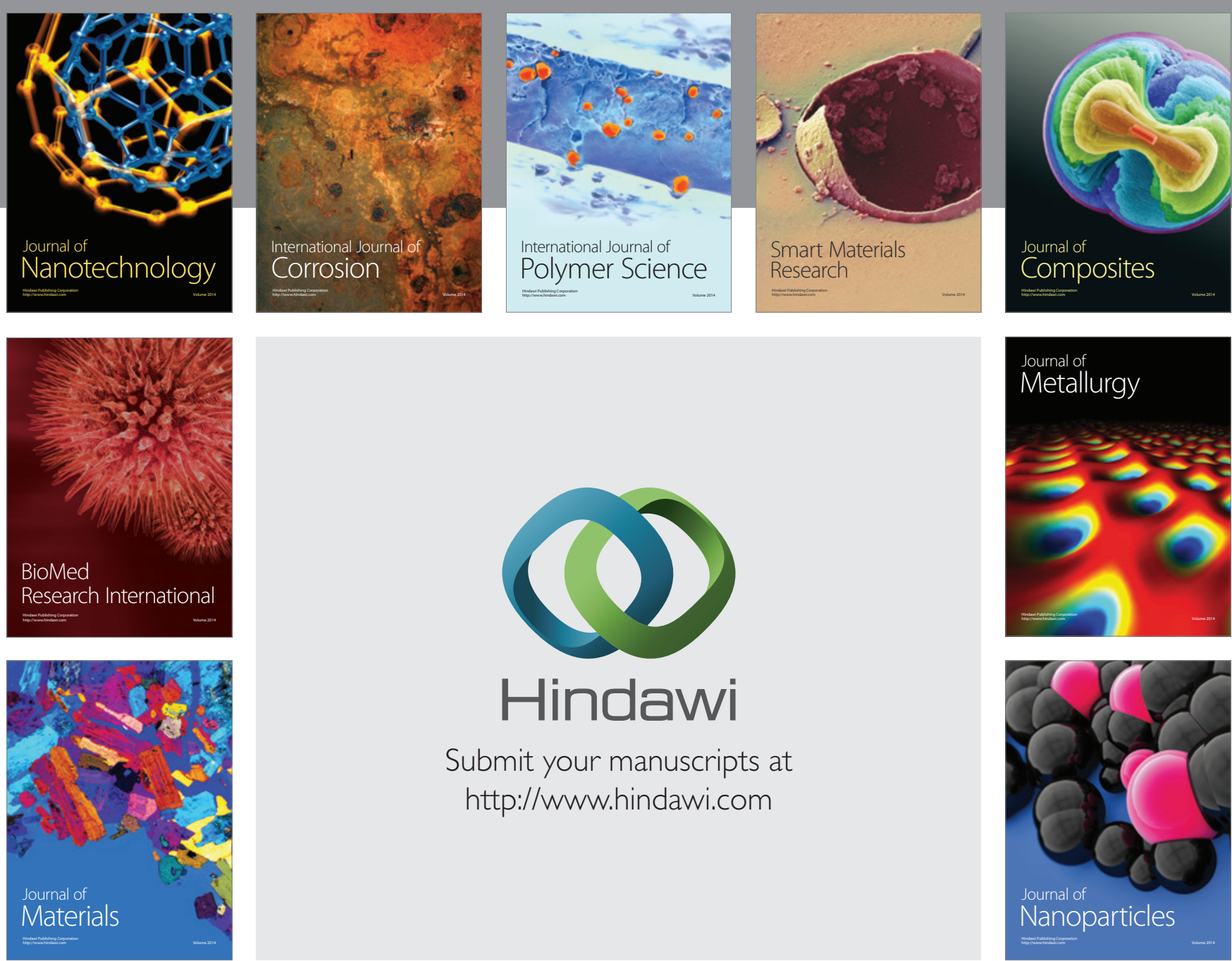

\section{Hindawi}

Submit your manuscripts at

http://www.hindawi.com

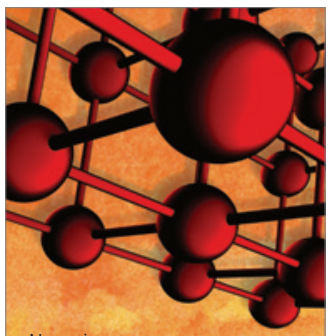

Materials Science and Engineering
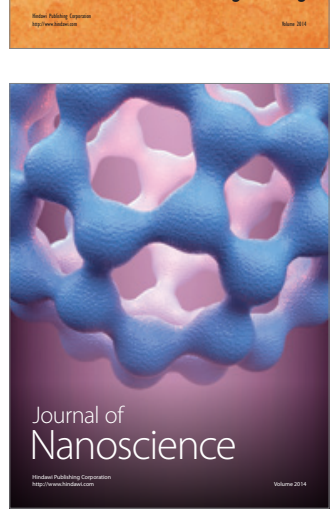
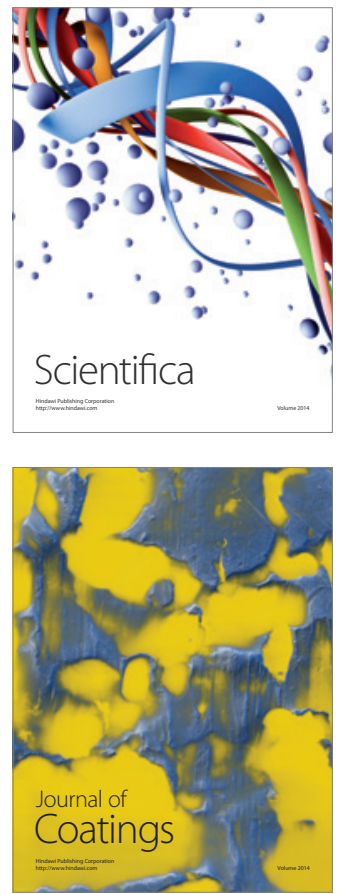
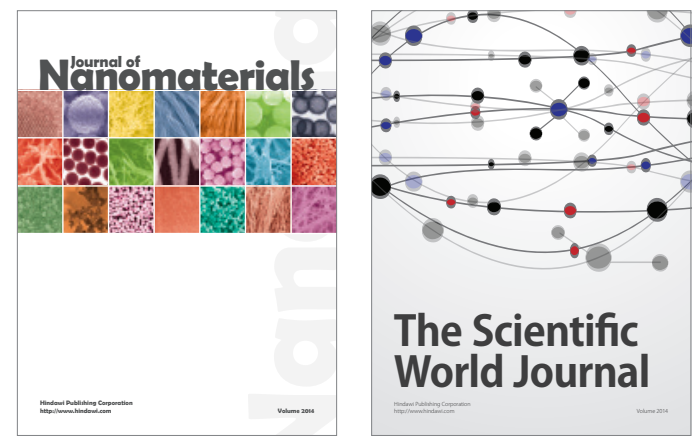

The Scientific World Journal
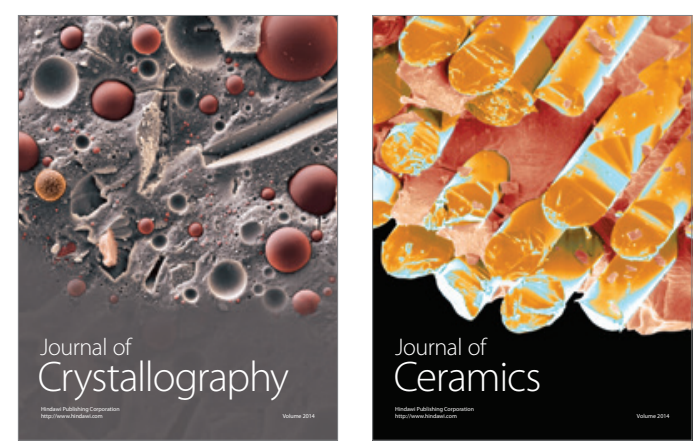
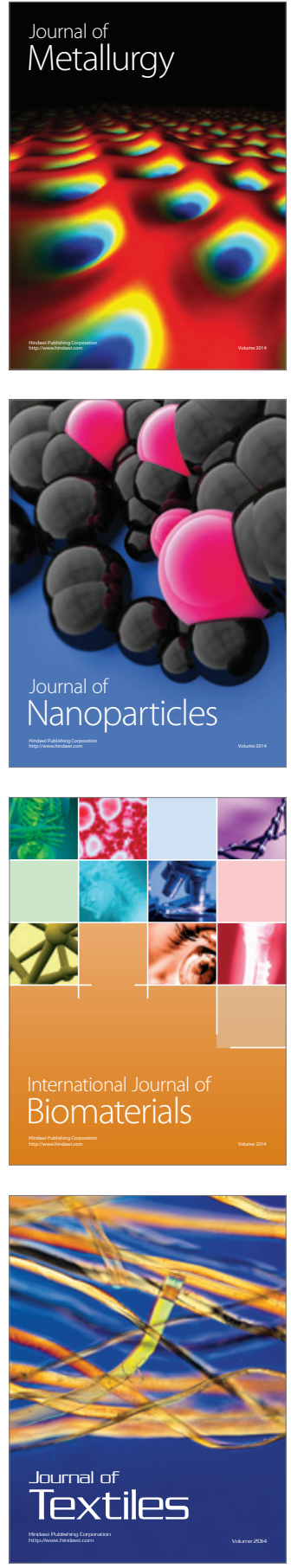